\title{
Almanac 2011: Cardiac Arrhythmias and Pacing. The National Society Journals Present Selected Research that has Driven Recent Advances in Clinical Cardiology
}

\author{
Reginald Liew \\ Department of Cardiology, National Heart Centre Singapore, Duke-NUS Graduate Medical School, Singapore, Singapore
}

\section{EDITORIAL}

\section{ATRIAL FIBRILLATION}

\subsection{Clinical trials}

In the past 2 years, a number of landmark clinical trials have been published which further our understanding and clinical management of patients with atrial fibrillation (AF). Two of the major goals in the treatment of this condition include reducing progression or recurrence of the arrhythmia and decreasing the risk of cardiovascular events, thereby improving quality of life and decreasing morbidity. Following on from a large body of evidence from preclinical studies, small clinical trials and meta-analyses suggesting that blockade of the renin-angiotensin system has beneficial effects on the pathophysiology of AF, $\frac{1}{\text { two }}$ large multicentre, placebo-controlled, randomised trials were conducted to determine the effects of angiotensin II receptor blockers (ARBs) on AF.

The first of these trials, published in 2009, tested the hypothesis that the ARB valsartan could reduce the recurrence of AF in patients with underlying cardiovascular disease, diabetes or left atrial enlargement and a history of documented AF, in addition to established treatments. ${ }^{2}$ A total of 1442 patients were enrolled into the study-722 assigned to the valsartan group (target dose $320 \mathrm{mg}$ ) and 720 to the placebo group. The investigators found that treatment with valsartan had no significant effect on AF recurrence (AF recurrence $51.4 \%$ in the valsartan group and $52.1 \%$ in the placebo group, $\mathrm{p}=0.73$ ) over a relatively short follow-up period of 1 year.

The second large ARB randomised controlled trial (RCT) published this year evaluated whether irbesartan would reduce the risk of cardiovascular events in patients with AF. - Patients with a history of risk factors for stroke and a systolic blood pressure of at least $110 \mathrm{~mm} \mathrm{Hg}$ were randomly assigned to receive either irbesartan (target dose of $300 \mathrm{mg}$ once daily) or placebo. Patients for this study were already enrolled in one of two other AF trials looking at clopidogrel plus aspirin versus aspirin alone or versus oral anticoagulants. The investigators found that irbesartan did not reduce cardiovascular events or hospitalisation rates for AF (total of 9016 enrolled with a mean follow-up of 4.1 years) and that, not surprisingly, more patients in the irbesartan group had symptomatic hypotension and renal dysfunction than those in the placebo group.

Although the main findings from both of these large RCTs were negative, it should be noted that they were secondary prevention studies-that is, patients already had established AF, and also had more advanced stages of disease (over $80 \%$ of patients in both studies had a history of persistent or permanent $\mathrm{AF}$ ), implying that the substrate for AF was already well established in both study groups. It might be argued that blockade of the renin-angiotensin system may be a more effective strategy if performed earlier during the natural history of the disease or even before $\mathrm{AF}$ develops (ie, primary prevention), since ACE inhibitors and ARBs may prevent, but not necessarily reverse, the electrical and structural remodelling that leads to the development and progression of the arrhythmia. In support of this, a smaller randomised single-centre study of 62 patients with lone AF, with no history of hypertension or heart disease, presenting to the emergency department reported that patients given ramipril (5 $\mathrm{mg}$ /day) had significantly fewer AF relapses during a 3-year follow-up period than patients given placebo. ${ }^{4}$

A significant new addition to the pharmacological options available for treating AF has been the emergence of dronedarone, a multichannel blocker with similar structural and electrophysiological properties to amiodarone with the main exception being removal of iodine and the addition of a methane-sulphonyl group. $\frac{5}{-}$ These structural changes result in decreased lipophilicity, shortened halflife (to approximately $24 \mathrm{~h}$ ), reduced tissue accumulation and theoretically fewer side effects than associated with amiodarone.

The ATHENA (A placebo-controlled, double-blind, parallel-arm Trial to assess the efficacy of dronedarone $400 \mathrm{mg}$ twice daily for the prevention of Hospitalisation or death from any cause in patiENts with Atrial fibrillation/ 
flutter) trial was a ground-breaking study published in early 2009 evaluating the effect of dronedarone on cardiovascular events in patients with AF. ${ }^{6}$ In this trial, 4628 patients with AF (paroxysmal or persistent) or atrial flutter who had an additional risk factor for death (age $\geq 70$ years, diabetes, history of stroke/transient ischaemic attack (TIA), systemic embolism, left atrial diameter $\geq 50 \quad \mathrm{~mm}$ and ejection fraction $\leq 40 \%$ ) were randomly assigned to receive dronedarone (400 mg twice daily) or placebo. Over a mean follow-up of $21 \pm 5$ months, the investigators found that patients in the dronedarone group had significantly lower primary outcome of first hospitalisation due to cardiovascular events or death than the placebo group (734 (32\%) vs 917 (39\%), respectively, $\mathrm{p}<0.001)$. Mortality from cardiac arrhythmias was significantly lower in the dronedarone group, although there was no overall difference in all-cause mortality. Interestingly, there was also a small but statistically significant reduction in acute coronary syndromes in the dronedarone group - the exact reason for this remains unclear. Patients taking dronedarone had higher rates of bradycardia, QTprolongation, nausea, diarrhoea, rash and increased serum creatinine than those receiving placebo. There were no significant differences in rates of thyroid- and pulmonaryrelated adverse events between the two groups, although, as acknowledged by the investigators in their discussion, the follow-up period of 21 months might have been too short to detect such adverse effects, which may take more than 2 years to develop, as is often observed with amiodarone.

In the original ATHENA trial and also a subsequent post hoc analysis, ${ }^{7}$ there was no evidence of harm in patients with heart failure or those with a low ejection fraction and New York Heart Association (NYHA) class II or III symptoms. This contrasts with results from the earlier ANDROMEDA (ANtiarrhythmic trial with DROnedarone in Moderate to severe congestive heart failure Evaluating morbidity DecreAse) study, which was terminated early owing to excess mortality in the dronedarone group. ${ }^{-}$The reason for this difference may be attributed to the exclusion of patients with NYHA class IV symptoms in the ATHENA study and the fact that the ANDROMEDA study also included patients with a recent exacerbation of heart failure. Nonetheless, in view of the results from the ANDROMEDA study, the authors warned against use of dronedarone in patients with severe heart failure and left ventricular dysfunction. This is reflected in the latest European and American guidelines, which propose that dronedarone can be used as a first-line pharmacological option in patients with symptomatic $\mathrm{AF}$, including those with structural heart disease, coronary artery disease, hypertensive heart disease and stable heart failure with NYHA class I or II symptoms, but should not be used in patients with NYHA class III or IV symptoms or recently unstable heart failure. ${ }^{910}$ A number of post hoc analyses of the ATHENA trial have been published providing further evidence for several beneficial effects of dronedarone. These include a reduction in stroke risk from $1.8 \%$ a year to $1.2 \%$ a year, 11 and favourable effects on rhythm and rate control. ${ }^{12}$

Another newly emerging drug that may have a role in the pharmacological cardioversion of AF is the atrial-selective antiarrhythmic drug vernakalant (RSD1235). $\frac{13}{}$ Vernakalant is one of several new agents that have been designed to target atrial-specific ion channels and in doing so, theoretically reduce or limit the risk of ventricular proarrhythmia. In an open-label trial assessing the efficacy of vernakalant in the cardioversion of AF, the intravenous agent was found to convert $50.9 \%$ of patients with AF (out of a total of 236) to sinus rhythm with a median time to conversion of 14 min among responders..$^{14}$ There were no episodes of ventricular arrhythmias and the drug was relatively well tolerated, apart from 10 patients $(4.2 \%)$ who had to discontinue treatment owing to side effects (most commonly hypotension). In a more recent small randomised trial of 254 patients with recent onset AF (3-48 h duration), vernakalant (10 min infusion of $3 \mathrm{mg} / \mathrm{kg}$ followed by a second $10 \mathrm{~min}$ infusion of $2 \mathrm{mg} / \mathrm{kg}$ if patient was still in AF after a 15 min observation period) was compared with intravenous amiodarone $(5 \mathrm{mg} / \mathrm{kg}$ over $60 \mathrm{~min}$ followed by 50 mg maintenance infusion over $60 \mathrm{~min}) \cdot \frac{15}{.}$ A greater number of patients achieved the primary end point of conversion to sinus rhythm within $90 \mathrm{~min}$ in the vernakalant group compared with the amiodarone group (60/116 (51.7\%) compared with 6/116 (5.2\%), p<0.0001, respectively). The median time of cardioversion in the patients receiving vernakalant who responded was $11 \mathrm{~min}$ and this was associated with a higher rate of symptom relief than with amiodarone. Both drugs were well tolerated in this study and there were no cases of ventricular arrhythmias.

A small randomised study of 61 patients with heart failure and persistent AF contributed additional useful data towards the continuing topic of rate versus rhythm control in patients with heart failure and AF. $\frac{16}{6}$ Patients in this study were randomly assigned to a rhythm control strategy (oral amiodarone and electrical cardioversion) or rate control with $\beta$ blockers and/or digoxin (target heart rate $<80$ bpm at rest and $<110 \quad$ bpm after walking). The investigators found that restoration of sinus rhythm in patients with AF and heart failure improved quality of life and left ventricular function compared with a strategy of rate control $(66 \%$ in the rhythm control group were in sinus rhythm at 1 year and $90 \%$ in the rate control group achieved the target heart rate). For patients with AF for whom a rate control strategy has been decided upon, the optimal target heart rate has remained controversial. Guidelines have previously recommended strict rate control, although this was not based on clinical evidence. In an attempt to examine this issue, a prospective, multicentre, randomised trial was conducted to test the hypothesis that lenient rate control was not inferior to strict rate control in preventing cardiovascular events in patients with permanent AF. ${ }^{17}$ The investigators found that of the 614 patients recruited into the study, the frequencies of symptoms and adverse events were similar between patients assigned to a lenient rate control strategy (resting heart rate $<110 \quad \mathrm{bpm}$ ) and those assigned to a strict rate control strategy (resting heart rate $<80 \quad \mathrm{bpm}$ and heart rate during moderate exercise $<110 \mathrm{bpm}$ ). A lenient-control strategy was easier to achieve as more patients in this group attained their heart rate target compared with the strict-control group $(97.7 \%$ vs $67.0 \%, \mathrm{p}<0.001)$.

Despite some promising results from preclinical ex- 
periments and observational studies in humans, $\frac{18-20}{1 \text { the }}$ potentially beneficial effects of polyunsaturated fatty acids (PUFA) in atrial fibrillation have not been confirmed from the results of several prospective randomised trials reported recently. The largest and most comprehensive study to date designed to examine this subject was a prospective, multicentre, RCT of 663 patients with confirmed paroxysmal $(n=542)$ or persistent $(n=121)$ AF, with no substantial structural heart disease and in sinus rhythm at baseline. ${ }^{21}$ Patients were randomly assigned to take prescription PUFA (8 g/day) or placebo for the first 7 days, followed by PUFA (4 g/day) or placebo thereafter for 24 weeks. Despite the assigned treatment being relatively well tolerated in both groups and plasma levels of eicosapentaenoic and docosahexaenoic acid being significantly higher in the prescription group than in the placebo group at weeks 4 and 24, the investigators found no reduction in AF recurrence over 6 months between the two groups. Two smaller prospective, placebo-controlled, randomised studies investigating the effects of PUFA in patients after electrical cardioversion of $\mathrm{AF}^{22}$ and after cardiac surger $\mathrm{y}^{23}$ have failed to demonstrate a beneficial action of PUFA in decreasing the recurrence or incidence of AF.

\section{STRATEGIES TO DECREASE THROMBOEMBOLISM}

Important advances have been made in stroke prevention in patients with AF over the past 2 years, which are likely to have a significant impact on future clinical management. In the RE-LY study (Randomised Evaluation of Long-term anticoagulation therapY), two fixed doses (110 $\mathrm{mg}$ or 150 mg twice daily) of a new oral direct thrombin inhibitor, dabigatran, were compared with warfarin in over 18000 patients with AF and at least one additional risk factor for stroke. ${ }^{24}$ The investigators found that patients taking the $110 \mathrm{mg}$ dose of dabigatran had similar rates of stroke and systemic embolism to those receiving warfarin, but had lower rates of major haemorrhage, while subjects taking the 150 mg dose had lower rates of stroke and systemic embolism, with similar rates of major haemorrhage. Results from this study were so impressive that dabigatran has since been incorporated into the latest European and American guidelines on AF as an alternative to warfarin for the prevention of stroke and systemic embolism in patients with paroxysmal and permanent AF. 925

As $80 \%$ of the active drug is excreted by the kidneys, patients with a creatinine clearance of $<30 \mathrm{ml} / \mathrm{min}$ were excluded from the RE-LY trial; dabigatran should be used with caution in patients with significant renal impairment. The dose of dabigatran approved by the US Food and Drug Administration in October 2010 was 150 mg twice daily in patients with non-valvular AF with a reduced dose of 75 mg twice daily for those with mild renal impairment (creatinine clearance of 15-30 $\mathrm{ml} / \mathrm{min}$ ). There are no dosing recommendations for patients with a creatinine clearance $<15 \mathrm{ml} / \mathrm{min}$ or those undergoing dialysis. In addition to the superiority of dabigatran (150 mg twice daily) over warfarin for treatment of stroke and systemic embolism, another major advantage is that there is no need for inter- national normalisation ratio (INR) monitoring. However, disadvantages include the lack of a specific antidote (its half-life is 12-17 h) and a slightly increased risk of nonhaemorrhagic side effects, including dyspepsia. How this promising new oral anticoagulant drug will be incorporated into current local practices around the world will require future evaluation and consideration. For example, there may be little to be gained from switching patients already receiving warfarin and with excellent INR control to dabigatran, while patients with poor INR control or those who have newly started oral anticoagulation may derive greater benefit. Local standards of care for anticoagulation control and follow-up may also be an important consideration, as concluded in a subanalysis of the RE-LY study, in which the investigators found that sites with poor INR control and greater bleeding from warfarin may receive greater benefit from dabigatran $150 \mathrm{mg}$ twice daily. $\frac{26}{}$ Other substudies following on from the original RE-LY trial have shown that the benefits of dabigatran are similar between patients who have never received a vitamin $\mathrm{K}$ antagonist (VKAnaive patients) and VKA-experienced patients, ${ }^{27}$ and that dabigatran can be used as a safe alternative to warfarin in patients requiring cardioversion. $\underline{28}$

In the ACTIVE A study, the ACTIVE (AF Clopidogrel Trial with Irbesartan for prevention of Vascular Events) investigators evaluated whether the addition of clopidogrel to aspirin would reduce the risk of vascular events compared with aspirin alone in patients for whom a VKA was considered unsuitable. ${ }^{29}$ The ACTIVE W trial had previously demonstrated that the combination of aspirin and clopidogrel was inferior to oral anticoagulation for the prevention of vascular events in patients with $\mathrm{AF}$ at high risk of stroke. $\frac{30}{}$ In the ACTIVE A study, involving 7554 patients and a median follow-up of 3.6 years, the investigators found that the combination of both antiplatelet agents reduced the risk of major vascular events, especially stroke, compared with aspirin alone but at the price of increased risk of major haemorrhage. The clinical implications of the ACTIVE A and ACTIVE $\mathrm{W}$ trials are that oral anticoagulation is better than the combination of aspirin and clopidogrel in stroke prevention in patients with AF, but for patients for whom oral anticoagulation is unsuitable, the combination of antiplatelet agents is better than aspirin alone, although the risk of major haemorrhage is also greater. This reinforces the need for appropriate counselling and risk stratification of patients when deciding upon the most suitable strategy to lower the risk of vascular events in patients with AF.

Another important randomised controlled clinical trial including patients for whom a VKA was not suitable involved the use of new oral direct and competitive inhibitor of factor Xa, apixaban. $\frac{31}{\text { The AVERROES (Apixaban vs }}$ acetylsalicylic acid to prevent stroke in patients with AF who have are unsuitable for vitamin $\mathrm{K}$ antagonist treatment or for whom this treatment has failed) study involved the random assignment of 5599 patients with AF (involving 522 centres in 36 countries) to apixaban (5 mg twice daily) or aspirin (81-324 $\mathrm{mg} /$ day). .32 In that study, patients with AF were aged $\geq 50$ years and had to have at least one risk factor for stroke in addition to being unable to take a VKA, either because it had already been shown to be unsuitable or 
was deemed to be unsuitable. The investigators found that apixaban reduced the risk of stroke or systemic embolism without significantly increasing the risk of bleeding or intracranial haemorrhage and also reduced the risk of a first hospitalisation for a cardiovascular cause.

Recent studies in the field of new mechanical approaches to stroke prevention in AF include the PROTECT AF (Watchman Left Atrial Appendage System for Embolic Protection in Patients with AF) study. $\frac{33}{}$ In this non-inferiority study, the efficacy and safety of a new percutaneous left atrial appendage (LAA) closure device was compared with warfarin treatment in 707 patients with non-valvular AF. Study participants had to have at least one risk factor for stroke (in addition to AF) and were assigned in a 2:1 ratio to receive the LAA-closure device and subsequent discontinuation of warfarin or warfarin alone (with a target INR of between 2.0 and 3.0). The LAA-closure device was successfully implanted in $88 \%$ of subjects assigned to the intervention group. After a mean follow-up of $18 \pm 10$ months, the primary efficacy event rate of stroke (ischaemic or haemorrhagic) was 3.0 per 100 patient-years (95\% CI 1.9 to 4.5 ) in the intervention group and 4.9 per 100 patient-years $(95 \%$ CI 2.8 to 7.1 ) in the control group. Primary safety events were more common in the intervention group than in the control group, and were mainly related to periprocedural complications (pericardial effusion in $4.8 \%$, major bleeding in 3.5\% and periprocedural ischaemic stroke in 1.1\%). This important study demonstrates that the Watchman (Atritech, Plymouth, Minnesota, USA) LAA-closure device may provide an alternative strategy to oral anticoagulation for the prevention of stroke in patients at high risk with non-valvular AF and at high thromboembolic risk, although the trade-off is an increased risk of periprocedural complications related to device implantation. As with all new interventional procedures, safety of the Watchman LAA-closure device is likely to improve with increased operator experience and familiarity with the new technology $\cdot \frac{34}{}$ Longer-term follow-up data with an earlier percutaneous LAA-closure device, PLAATO (percutaneous left atrial appendage transcatheter occlusion) system,,$\frac{35}{}$ suggest that such devices can lower the annualised risk of stroke/ TIA compared with the expected stroke/TIA risk assessed using the CHADS2 score $(3.8 \%$ a year and $6.6 \%$ a year, respectively), although event rates still remain significant. $\frac{36}{}$

\section{EPIDEMIOLOGY AND GENETICS OF AF}

Epidemiological studies have shed further light on the mechanisms underlying AF and identified new risk factors. Using data from the Framingham Heart Study, investigators identified a prolonged PR interval $(>200 \mathrm{~ms})$ as a predictor of incident AF, pacemaker implantation and all-cause mortality in 7575 individuals (mean age 47 years; 54\% women). ${ }^{37}$ This study contradicts the previously held belief that first-degree heart block is benign ${ }^{38}$ and raises further questions about the mechanism by which a prolonged PR interval might increase the risk of developing AF. In another study using 4764 participants from the Framingham Heart Study, a new risk score was developed aimed at predicting an individual's absolute risk for developing AF. ${ }^{39}$ Age, sex, body mass index, systolic blood pressure, treatment for hypertension, PR interval, clinically significant cardiac murmur and heart failure were all found to be associated with AF ( $\mathrm{p}<0.05$, except body mass index $\mathrm{p}=0.08)$. When incorporated in a risk score, the clinical model C statistic was 0.78 (95\% CI 0.76 to 0.80 ).

In a subsequent study, the same investigators looked at the relation between a number of plasma biomarkers and incident AF using the Framingham cohort and found that B-type natriuretic peptide (BNP) was a predictor of incident $\mathrm{AF}$ and improved risk stratification, increasing the C statistic from 0.78 (95\% CI 0.75 to 0.81$)$ to 0.80 (95\% CI 0.78 to 0.83$).{ }^{40}$

In another community-based population study of older adults $(\mathrm{n}=5445)$ who participated in the Cardiovascular Health Study, NT-proBNP was found to predict new-onset AF, independently of any other previously described risk factor. ${ }^{41}$ Similar findings have now been reported in a Finnish cohort. ${ }^{42}$ The potential role of biomarkers may extend beyond predicting incident $\mathrm{AF}$ - a recent study reporting that the kinetics of plasma NT-proBNP release in patients presenting acutely with AF provides a potential means of determining its time of onset and the safety of cardioversion. ${ }^{43}$ There therefore appears to be a promising role for new biomarkers in predicting incident $\mathrm{AF}$, which may help guide clinicians as to which individuals are most at risk of developing AF and who may benefit from prophylactic treatments. Other studies looking at population data in women have reported body-mass index ${ }^{44}$ and birth weight ${ }^{45}$ to be associated with incident AF. Furthermore, recent data from 34722 participants of the Women's Health Study provided evidence that new-onset AF in initially healthy women was independently associated with all-cause and cardiovascular mortality. ${ }^{46}$

The past 2 years have seen important advances in our understanding of the genetics and heredity of AF. Following the landmark discovery using genome-wide association studies on subjects from European and Chinese descent that two sequence variations on chromosome $4 \mathrm{q} 25$ are associated with an increased risk of developing AF, ${ }^{47}$ two new AF susceptibility signals have been identified on the same chromosome. ${ }^{48}$ A meta-analysis of four independent cohorts of European descent (the Framingham Heart Study, Rotterdam Study, Vanderbilt AF Registry and German AF Network) confirmed a significant relationship between AF and intergenic regions on chromosome $4 .{ }^{49}$ Interestingly, genetic variants in the chromosome $4 \mathrm{q} 25$ region also appear to modulate the risk of AF recurrence after catheter ablation ${ }^{50}$ and are associated with the development of AF after cardiac surgery. ${ }^{51}{ }^{52}$ Whether genetic sequencing of chromosome $4 \mathrm{q} 25$ will prove useful in risk stratification for the development of AF after catheter ablation or cardiac surgery remains to be determined-at present, this remains a distinct and promising possibility. In line with the newly emerging genetic data on AF, studies on population-based cohorts have also provided evidence for a heredity component. Using data from the Framingham Heart Study, investigators found that familial AF occurred in 1185 (26.8\%) and premature familial AF occurred among 
351 (7.9\%) participants out of 4421 participants (11 971 examinations) during the period $1968-2007 .{ }^{53}$ The association was not attenuated by adjustment for AF risk factors or reported AF-related genetic variants. Racial factors and ancestry also appear to be related to the risk of AF. Data from white and African-American subjects enrolled in the Cardiovascular Health Study (CHS) and Atherosclerosis Risk in Communities (ARIC) study suggest that European ancestry is a risk factor for incident $\mathrm{AF}^{54}$

\section{CATHETER ABLATION OF AF}

In a large prospective, multicentre trial involving 19 centres, the use of catheter ablation was compared with antiarrhythmic drug treatment. ${ }^{55}$ A total of 167 patients with paroxysmal AF for whom at least one antiarrhythmic drug had failed and who had experienced at least three AF episodes in the preceding 6 months were randomised (2:1) to undergo catheter ablation or medical treatment. After a 9 month follow-up period, the investigators found that catheter ablation resulted in a longer time to treatment failure and significantly improved quality-of-life scores. Major 30-day treatment-related adverse events occurred in five of 103 patients $(4.9 \%)$ treated with catheter ablation and five of 57 patients (8.8\%) treated with antiarrhythmic drugs. An improvement in the quality of life was also demonstrated in a prospective follow-up study of 502 symptomatic subjects who underwent AF ablation. ${ }^{56}$ The improvement in quality of life was sustained at 2 years in patients with and without recurrence of $\mathrm{AF}$, although the change was greatest in patients who remained free from AF and without antiarrhythmic drug treatment.

Several well-respected, high-volume centres have recently published their long-term outcomes following catheter ablation for AF. The Bordeaux group reported their 5 year follow-up data on 100 patients (86\% male; age $55.7 \pm 9.6$ years; $63 \%$ paroxysmal AF; $36 \%$ with structural heart disease). ${ }^{57}$ Arrhythmia-free survival rates after a single catheter ablation procedure were $40 \%, 37 \%$ and $29 \%$ at 1 , 2 and 5 years, respectively (most recurrences occurred over the first 6 months). A total of 175 procedures were performed with a median of two for each patient (51 patients underwent a second procedure and 17 a third). There were no periprocedural deaths, although major complications (cardiac tamponade requiring drainage) occurred in three patients (3\%), and minor complications (arteriovenous (AV) fistula, femoral pseudoaneurysm and asymptomatic pulmonary vein stenosis) occurred in another three patients. The important point to note from this study is that even in experienced hands with a selected AF population (patients who are referred for AF ablation tend to be younger and have fewer comorbidities), there is a steady decline in arrhythmia-free survival with recurrences seen up to 5 years after ablation, although the majority occur within the first 6-12 months.

An experienced German centre also recently reported their long-term follow-up data of catheter ablation in 161 patients (75\% male; age 59.8 \pm 9.7 years) with symptomatic paroxysmal AF and normal left ventricular function. ${ }^{58}$ They found that 75 patients (46.6\%) were in sinus rhythm after the initial procedure during a median follow-up period of
4.8 years (0.33 to 5.5 years). A second procedure was performed in 66 and a third procedure in 12 patients. One patient had an aspiration pneumonia that was successfully treated and two developed a sterile pericardial effusion that did not require drainage (no other procedural complications were noted). There was a low rate of progression to chronic AF during the follow-up period, which was seen in only four patients (2.5\%).

A group from London, $\mathrm{UK}$, similarly reported their long-term results following catheter ablation for AF in 285 patients (75\% male; mean age 57 (SD 11) years; 53\% paroxysmal AF; $20 \%$ with structural heart disease) undergoing a total of 530 procedures. ${ }^{59}$ During a mean follow-up of 2.7 years (0.2 to 7.4 years), freedom from AF/atrial tachyarrhythmia was $86 \%$ for patients with paroxysmal $\mathrm{AF}$ and $68 \%$ for those with persistent AF. Complications included three strokes/TIAs. Late recurrence was three per 100 years of follow-up after $>3$ years. The investigators also found that targeting complex fractionated atrial electrograms (CFAEs) during the ablation procedure improved outcome in patients with persistent AF. However, this was not seen in a randomised study performed by another group in which 119 patients with persistent AF were randomised to additional CFAE ablation following pulmonary vein isolation or no additional ablation. ${ }^{60}$

In summary, the reports on long-term success rates following catheter ablation for AF demonstrate that the procedure is effective in a selected group of symptomatic patients with AF, although a significant proportion require more than one ablation procedure, there are risks of periprocedural complications and AF recurrence remains a possible problem, even after follow-up periods as long as 5 years. It should be noted that reported outcomes from the different centres cannot be directly compared, since there are differences in patient population (eg, percentage of patients with paroxysmal and permanent AF, patients with structural heart disease), techniques used (segmental pulmonary vein isolation vs wide area circumferential ablation), length of follow-up and methods used to detect AF recurrence.

A number of studies have been performed to search for new non-invasive parameters which may help to predict AF recurrence following catheter ablation. These factors include renal impairment, ${ }^{61}$ novel echo parameters such as the atrial electromechanical interval, ${ }^{62}$ atrial fibrosis assessed with echo ${ }^{63}$ or MRI ${ }^{64}$ and B-type natriuretic levels. ${ }^{65}$

\section{VENTRICULAR ARRHYTHMIAS AND SUDDEN CARDIAC DEATH}

\subsection{Ventricular arrhythmias after myocardial infarction}

To further understand the significance of the occurrence and timing of ventricular arrhythmias in the context of primary percutaneous coronary intervention (PCI), a secondary analysis of the APEX AMI (Assessment of PEXelizumab in Acute Myocardial Infarction) trial was undertaken. ${ }^{66}$ Of the 5745 patients with ST-elevation myocardial infarction presenting for primary PCI (across 296 hospitals in 17 countries), ventricular tachycardia/ventricular fibril- 
lation (VT/VF) occurred in 329 (5.7\%). Clinical outcomes and 90-day mortality were found to be worse in those with VT/VF than in those without. Furthermore, outcomes were worse if the VT/VF occurred late (after the end of cardiac catheterisation) rather than early (before the end of cardiac catheterisation). The occurrence of ventricular arrhythmias remained associated with a significantly increased mortality after adjustment for potential confounders, although whether they were causally related to a poorer prognosis or simply a reflection of more severe heart disease is not yet clear.

In the Occluded Artery Trial-Electrophysiological Mechanisms (OAT-EP) study, PCI to open a persistently occluded infarct-related artery after an acute myocardial infarction (AMI) phase was compared with optimal medical treatment alone to determine which strategy reduced markers of vulnerability to ventricular arrhythmias. ${ }^{67}$ There were no significant differences in heart rate variability, time-domain signal-averaged ECG, or T-wave variability parameters (all surrogate markers of ventricular instability) between either group at 30 days and 1 year after the AMI, which is consistent with the lack of clinical benefit from PCI in stable patients after AMI with persistently occluded infarct-related arteries in the main OAT study.

The Cardiac Arrhythmias and Risk Stratification After Myocardial Infarction (CARISMA) trial was designed to investigate the incidence and prognostic significance of arrhythmias detected by an implantable cardiac monitor among patients after AMI with impaired left ventricular (LV) function. ${ }^{68}$ A total of 297 patients (out of 5969 initially screened) who had had a recent AMI and had reduced LV ejection fraction (LVEF; $\leq 40 \%)$ received an implantable loop recorder within $11 \pm 5$ days of the AMI and were followed up every 3 months for an average of $1.9 \pm 0.5$ years. The investigators detected a clinically significant number of bradyarrhythmias and tachyarrhythmias in these patients (28\% new-onset AF, 13\% non-sustained VT, 10\% high-degree AV block, 7\% significant sinus bradycardia, 3\% sinus arrest, 3\% sustained VT and 3\% VF). In particular, intermittent high-degree AV block was associated with a very high risk of cardiac death. The arrhythmogenic substrate for ventricular arrhythmias following reperfusion therapy for AMI was investigated in a study of 36 AMI survivors referred for catheter ablation of VT $(13 \pm 9$ years after the AMI) ${ }^{69}$ Of these, 14 patients had early reperfusion during AMI, while 22 were non-reperfused. The investigators found, using detailed electroanatomical mapping, that scar size and pattern were different between VT patients with and without reperfusion during AMI, with early reperfusion and less confluent electroanatomical scar being associated with faster VTs.

\subsection{Risk stratification for sudden cardiac death and implantable cardioverter defibrillators}

A continuing area of active research in ventricular arrhythmias and sudden cardiac death (SCD) is in improved methods of risk stratification and selection of appropriate implantable cardioverter defibrillator (ICD) recipients. ${ }^{70} \mathrm{~A}$ number of non-invasive cardiovascular tests have recently been evaluated among patients with an increased risk of SCD (eg, AMI survivors and patients with coronary artery disease and cardiomyopathies) with promising results. These include T-wave alternans, ${ }^{712}$ single-photon emission CT myocardial perfusion imaging, ${ }^{73}$ sympathetic nerve imaging with 123-iodine metaiodobenzylguanidine $e^{74}$ and late-gadolinium enhancement on cardiac MRI. ${ }^{75}$ In addition, plasma biomarkers, such as serum collagen levels, which reflect extracellular matrix alterations that may play a part in the generation of the arrhythmogenic substrate, ${ }^{76}$ may have a future role in risk stratification. Genetic markers may also be relevant, as suggested by the observation from a combined population of 19295 black and white adults from the Atherosclerosis Risk In Communities Study and the Cardiovascular Health Study that sequence variations in the nitric oxide synthase 1 adaptor protein (NOS1AP) were associated with baseline QT interval and the risk of SCD in white (but not black) US adults. ${ }^{778}$

Another important area requiring further clarification is the optimal timing of ICD insertion among AMI survivors who are deemed to be at greatest risk of SCD. The landmark DINAMIT study (Defibrillation IN Acute Myocardial Infarction Trial), which did not show any mortality benefit from prophylactic ICD insertion in patients after AMI if the device was inserted within 40 days of the index event, ${ }^{79}$ has been used to guide current recommendations on ICD insertion among AMI survivors. A recent secondary analysis of this trial confirmed the original findings that the reduction in sudden death in ICD patients was offset by an increase in non-arrhythmic deaths, which was greatest in those who received ICD shocks. ${ }^{80}$

A postmortem study looking at 105 autopsy records of patients from the VALIANT (VALsartan In Acute myocardial infarctioN Trial) study who had died suddenly showed that recurrent myocardial infarction or cardiac rupture accounted for a high proportion of sudden death in the early period after an AMI, thereby partly explaining the lack of benefit of early ICD insertion on overall mortality. ${ }^{81}$ Arrhythmic death was more likely to occur later on (after 3 months), which is consistent with the findings of improved survival among ICD recipients from other major ICD trials in which the devices were inserted at a later stage. It should be noted, however, that $20 \%$ of sudden deaths in the first month after AMI were presumed arrhythmic as there was no specific postmortem evidence of any additional abnormality that might have caused the sudden death. A significant proportion of patients who have an AMI therefore appear to continue to die suddenly in the early postinfarction period from cardiac arrhythmias. These patients are not included in current international guidelines for ICD insertion and remain a group for which more research is required. Another group of patients who are not covered by current primary prevention ICD guidelines are those with relatively preserved LVEF after an AMI. Although these patients are at lower risk of SCD than those with poor LVEF, they represent a larger proportion of AMI survivors.

Data from a multicentre Japanese study suggest that in the era of primary PCI there is a low incidence of SCD among AMI survivors (overall mortality was $13.1 \%$ and SCD 1.2\% over an average follow-up period of 4.2 years among 4122 patients). ${ }^{82}$ The risk was highest for those with 
poor LVEF $(<30 \%)$, although the absolute number at risk was greatest in those with relatively preserved LVEF (>40\%).

The Intermediate Risk Stratification Improves Survival (IRIS) trial published in 2009 further tested the hypothesis that early implantation of an ICD soon after an AMI could improve survival compared with optimal medical treatment. ${ }^{83}$ This was a randomised, prospective, multicentre trial which enrolled 898 patients, 5-31 days after their AMI, who met the following clinical criteria: LVEF $\leq 40 \%$ and a heart rate $\geq 90 \quad \mathrm{bpm}$ on the first available ECG or non-sustained VT $(\geq 150 \mathrm{bpm})$ during Holter monitoring. The main difference between this study and DINAMIT was a contemporary patient population (70\% had undergone PCI and the majority were receiving optimal long-term medication) and additional non-invasive criteria to identify a population at potentially higher risk. However, the investigators did not find that ICD therapy reduced overall mortality after a mean follow-up of 37 months. Consistent with the findings from DINAMIT, the reduced incidence of SCD among ICD recipients in the IRIS study was offset by an increased incidence of non-SCD.

Catheter ablation of ventricular arrhythmias

The VTACH (Ventricular Tachycardia Ablation in Coronary Heart disease) study, involving 16 centres in four European countries, assessed the potential benefit of catheter ablation of VT before ICD implantation in patients with a history of VT, myocardial infarction and LVEF $\leq 50 \% .{ }^{84}$ Patients $(n=110)$ were randomly allocated to receive catheter ablation and an ICD or an ICD alone and followed-up for a mean period of 22.5 months (SD 9.0). The investigators found that prophylactic VT ablation before ICD implantation prolonged the time to VT recurrence from 5.9 months (IQR 0.8-26.7) in the ICD only group to 18.6 months (lower quartile 2.4 months; upper quartile could not be determined) in the ablation and ICD group. Complications related to the ablation procedure occurred in two patients. This study is in accordance with an earlier prospective randomised study of 128 patients, which demonstrated that prophylactic catheter ablation of the ventricular arrhythmogenic substrate reduced the incidence of ICD therapy in patients with a history of myocardial infarction and previous ventricular arrhythmias. ${ }^{85}$ It should be noted that VT ablation was performed in experienced centres in both these trials and that there was no significant effect of catheter ablation on overall mortality. Whether VT ablation should routinely be performed before ICD insertion for secondary prevention of SCD in stable patients with previous myocardial infarction remains to be determined.

There has been an increase in the number of publications on epicardial ablation for VT over the past few years in view of the realisation that not all VTs can be successfully eliminated by an endocardial-only approach. ${ }^{8687}$ In a retrospective study of 156 epicardial ablations for VT (out of a total of 913 VT ablations) in three tertiary centres evaluating the safety and mid-term complications of epicardial VT ablation, the risk of major acute (epicardial bleeding, coronary stenosis) and delayed (pericardial inflammatory reaction, delayed tamponade, coronary occlusion) complications related to epicardial access was found to be $5 \%$ and
$2 \%$, respectively. ${ }^{88}$ Therefore, although this technique can be effective in some cases, especially where endocardial ablation has failed, it is associated with significant morbidity and should only be performed in centres experienced with this technique.

The prognostic significance of frequent premature ventricular contractions (PVCs) and the effect of catheter ablation of these ectopics has received further attention recently. In a study of 239 asymptomatic patients with structurally normal hearts and frequent PVCs (>1000/day) from the right or left ventricular outflow tract, a significant negative correlation between PVC prevalence and $\delta$ LVEF and positive correlation with $\delta \mathrm{LV}$ diastolic diameter was observed over a 5.6 (SD 1.7)-year period ${ }^{89}$ In addition to PVC burden, other factors such as longer PVC duration, presence of non-sustained VT, multiform PVCs and right ventricular PVCs may be associated with a decline in LV function. ${ }^{90}$ ${ }^{91}$ Although it is well known that catheter ablation of frequent PVCs can improve and restore LV function in some patients, the potential benefits of ablation in patients with normal LV function have been less well studied. A prospective study of 49 patients with frequent PVCs and normal baseline LVEF demonstrated that catheter ablation can improve the subtle LV dysfunction-detected pre-ablation using speckle tracking imaging analysis. ${ }^{92}$ However, unanswered questions remain, including benefits of catheter ablation on hard end points (especially mortality) and when ablation should be performed (degree of PVC burden, LV function, after a trial of antiarrhythmic medication?).

\subsection{Cardiac resynchronisation therapy and pacing}

Two pivotal cardiac resynchronisation therapy (CRT) clinical trials have been published in the past 2 years that potentially expand the indications for CRT in patients with heart failure to those in NYHA class I and II symptoms. MADIT-CRT (Multicenter Automatic Defibrillator Implantation Trial-CRT) compared the use of ICD alone with CRT-D (CRT with a defibrillator component) in patients with asymptomatic or mildly symptomatic heart failure symptoms (NYHA class I or II), LVEF $\leq 30 \%$ and QRS duration of $\geq 130 \mathrm{~ms} .{ }^{93}$ During an average follow-up of 2.4 years, fewer patients in the CRT-D group experienced the primary composite end point (all-cause mortality and heart failure) compared with the ICD group (17.2\% compared with $25.3 \%$, respectively, $\mathrm{p}=0.001$ ). Although these results appear impressive at first glance, closer examination of the data reveals that the main superiority of CRT-D was in reducing the rate of hospitalisation for heart failure and that there was no significant difference in mortality between the two groups (which was 3\% annually). Furthermore, the study failed to show that NYHA class I patients fulfilling the enrolment criteria benefited from CRT-D.

In RAFT (Resynchronisation-Defibrillation for Ambulatory Heart Failure Trial), CRT-D was compared with ICD alone in patients with NYHA class II or III heart failure, $\mathrm{LVEF} \leq 30 \%$, intrinsic QRS duration $\geq 120$ ms or a paced QRS duration of $\geq 200 \mathrm{~ms} .^{94}$ The investigators found that over a mean period of 40 months, the primary outcome (all-cause mortality or heart failure hospitalisation) occurred in fewer patients in the CRT-D group $(33.2 \%$ compared with $40.3 \%$ in the ICD group, $\mathrm{p}<0.001)$. Unlike 
MADIT-CRT, RAFT demonstrated that CRT-D significantly reduced overall mortality and cardiovascular mortality compared with ICD alone, although more adverse device-related events were also seen in the CRT-D group. Possible reasons for mortality benefit seen in RAFT, but not MADIT-CRT, are that RAFT included patients with more advanced disease (and a higher proportion with ischaemic heart disease) and follow-up was longer and more complete.

A number of subanalyses of MADIT-CRT have since been conducted to provide further information on the findings. One subanalysis demonstrated that women experienced significantly greater reductions in all-cause mortality and heart failure than men, which was accompanied by greater echo evidence of reverse cardiac remodelling. ${ }^{95}$ Another subanalysis looking specifically at the echo parameters and performance between the two groups found that CRT significantly improved cardiac size and performance compared with the ICD-only strategy, which probably accounted for the outcomes benefit in the CRT-D group. ${ }^{96}$ Other studies have also provided additional echo evidence that CRT in mild heart failure (NYHA class I/II) results in major structural and functional reverse remodelling which may prevent disease progression. ${ }^{97} 98$ The PACE (Pacing to Avoid Cardiac Enlargement) study explored whether biventricular pacing was better than right ventricular (RV) apical pacing in preventing adverse cardiac remodelling in patients with bradycardia and normal ventricular function at baseline. ${ }^{99}$ In this small randomised study of 177 patients followed up over a 12-month period, the investigators found that the mean LVEF was significantly lower in the RV-pacing group than in the biventricular-pacing group ( $54.8 \pm 9.1 \%$ vs $62.2 \pm 7.0 \%, \mathrm{p}<0.001)$, with an absolute difference of $7.4 \%$ points. However, the beneficial effects of biventricular pacing on echo parameters in this group of patients were not accompanied by any clinical benefit.

Other important and continuing areas of investigation in the field of CRT include how best to select candidates who are most likely to respond to CRT and how to optimise response. Parameters that have recently been studied to improve patient selection include QRS morphology in MADIT-CRT (left bundle branch block (LBBB), rather than non-LBBB, patterns appears to be the predominant morphology - that is, related to response), ${ }^{100}$ baseline LV radial dyssynchrony, discordant LV lead position, and myocardial scar in the region of the $\mathrm{LV}$ pacing lead, ${ }^{101}$ and pre-pacing systolic dyssynchrony measured by tissue Doppler imaging velocity. ${ }^{102}$ Consistent with existing knowledge, LV lead positioning has been reconfirmed to be important in MADIT-CRT patients ${ }^{103}$ and patients with non-ischaemic dilated cardiomyopathy. ${ }^{104}$ The prospective, randomised SMART-AV (SmartDelay determined AV optimisation: a comparison with other AV delay methods used in CRT) study compared three different methods of AV optimisation (fixed empirical AV delay of 120 ms, echo-optimised AV delay, or AV optimisation with an ECG-based algorithm) in 980 patients with a CRT device to determine if any method was superior. ${ }^{105}$ The study found that neither echo- or ECGbased AV optimisation was better than a fixed AV delay of $120 \mathrm{~ms}$ and therefore concluded that the routine use of AV optimisation techniques was not indicated. However, the data did not exclude the possibility that AV optimisation might have a role in selected patients who do not respond to CRT with empirical settings.

The potentially deleterious effects of chronic RV pacing on cardiac function were re-examined in 103 patients with isolated congenital AV block. Long-term pacing was not found to be associated with the development of heart failure or deterioration of ventricular function in patients who were negative for antinuclear antibody, although patients who tested positive for the antibody were more likely to develop heart failure. ${ }^{106}$ Pacing in hypertrophic cardiomyopathy was also recently re-examined in a singlecentre study, which found some evidence of benefit from dual chamber pacing in patients with hypertrophic cardiomyopathy with NYHA III-IV symptoms, rest gradients of $>50 \mathrm{~mm} \mathrm{Hg}$ and who were refractory to other drugs, after follow-up periods of up to 10 years. ${ }^{107}$ Another group of patients in whom the role of pacing has remained controversial are those with carotid sinus hypersensitivity (CSH) with syncope. In a double-blind, placebo-controlled, crossover study, 34 patients (aged $>55$ years) with $\mathrm{CSH}$ and more than three unexplained falls in the preceding 6 months were randomised to receive a dual-chamber pacemaker with rate-drop response programming which was switched on or off. ${ }^{108}$ The investigators found that the pacing intervention had no effect on the number of falls and concluded that the role of pacing for this group of patients remains controversial. A similar conclusion was reached in a multicentre study of 141 patients (mean age 78 years) with cardioinhibitory $\mathrm{CSH} .{ }^{109}$

\section{INHERITED ARRHYTHMOGENIC DISEASES}

Major advances have been made in our understanding of the basic mechanisms, genetics and clinical features of the inherited arrhythmogenic diseases (IADs) over the past 2 years. Since these cannot all be covered in this short overview, only some of the major studies with important implications for general cardiologists will be mentioned. The rapid expansion in our knowledge of the genetic basis of the IADs and rise in commercially available clinical genetic services has brought with it an additional dimension to how we manage these conditions. The reader is referred to a number of useful recently published reviews that examine these issues in more detail. ${ }^{110-112}$

SCD without morphological evidence of heart disease accounted for $23 \%$ of cases in a recent pathological study of UK athletes. ${ }^{113}$ Potential causes of unexplained cardiac arrest were systematically evaluated in a prospective study involving 63 patients in nine centres across Canada. ${ }^{114}$ The tests, which included cardiac MRI, signal-averaged ECG, exercise testing, drug challenge and selective electrophysiology (EP) testing, resulted in a specific diagnosis (IAD, early repolarisation, coronary spasm and myocarditis) in 35 patients (56\%). The remaining 28 patients were considered to have idiopathic VF. Subsequent genetic testing performed in 19 patients found evidence of causative mutations in nine (47\%) of these. Family screening of 64 family members of the nine patients with causative mutations led 
to the discovery of mutations in 15 individuals (23\%), who were subsequently treated. This study provides evidence that targeted genetic testing may play a part in helping to diagnose genetically mediated arrhythmia syndromes, which may result in successful family screening.

An important study that investigated the presence of genetic factors or modifiers that could partly explain the phenomenon of incomplete penetrance seen in congenital long QT syndrome (LQTS) identified the nitric oxide synthase 1 adaptor protein (NOS1AP) as one such candidate. ${ }^{115}$ This protein was chosen on the basis of previous studies that showed an association between genetic variants of NOS1AP and small quantitative increases in the QT interval and an increased risk of death in a general population. ${ }^{7716}$ In the study involving a South African LQTS population (500 subjects, 205 mutation carriers), NOS1AP variants were found to be significantly associated with the occurrence of symptoms, clinical severity (including cardiac arrest and SCD) and a greater likelihood of having a QT interval in the top $40 \%$ of values among all mutation carriers. In another study involving 901 patients enrolled in a prospective LQTS registry, three NOS1AP marker single nucleotide polymorphisms (SNPs rs4657139, rs16847548 and rs10494366) were genotyped to assess the effect of variant alleles on QTc and on the incidence of cardiac events. ${ }^{117}$ The investigators found that variant alleles tagged by SNPs rs4657139 and rs16847548 were associated with an average QTc prolongation of 7 and 8 ms, respectively, whereas rs4657139 and rs10494366 were associated with an increased incidence of cardiac events. Furthermore, the rs10494366 minor allele was an independent prognostic marker among patients with QTc $<500 \mathrm{~ms}$, but not in the entire cohort. These two studies demonstrate that genetic testing for variants in the NOS1AP and tagged SNPs may be clinically useful for risk stratification of patients with congenital LQTS and potentially guide the choice of therapeutic strategies.

The FINGER (France, Italy, Netherlands, GERmany) registry, one of the largest series on patients with Brugada syndrome $(\mathrm{BrS})$ so far, involved 1029 consecutive individuals (745 men; $72 \%$ ) with BrS (with a spontaneous or drug-induced type I ECG) who were followed up for a median period of 31.9 months. ${ }^{118}$ The cardiac event rate per year was $7.7 \%$ in patients with aborted SCD, $1.9 \%$ in patients with syncope and $0.5 \%$ in asymptomatic patients. This study provides important information that the event rate among asymptomatic patients with a Brugada ECG (which comprised 64\% of subjects in the registry) is low. In addition, symptoms and a spontaneous type 1 ECG were predictors of arrhythmic events, whereas gender, familial history of SCD, inducibility of VTs during an EP study and the presence of an SCN5A mutation were not predictive of arrhythmic events.

In an interesting mechanistic study of $\mathrm{BrS}$, in vivo high-density mapping using non-contact mapping array was performed in the right ventricle of 18 patients with BrS and 20 controls. ${ }^{119}$ The investigators identified marked regional endocardial conduction delay and heterogeneities in repolarisation in patients with $\mathrm{BrS}$ and proposed that the slow-conduction zones may have a role in the initiation and maintenance of ventricular arrhythmias.
In line with these findings, an outstanding study was subsequently performed in which nine symptomatic patients with BrS who had recurrent VF episodes underwent endocardial and epicardial mapping of the right ventricle. Ablation at unique abnormal low voltage sites (clustering exclusively in the anterior aspect of the RVOT epicardium) rendered VT/VF non-inducible in seven of the nine patients, with no recurrence of ventricular arrhythmias in all patients over a follow-up period of $20 \pm 6$ months. Interestingly, normalisation of the Brugada ECG pattern was seen in eight patients after ablation. This important proof-of-concept study lends further support to the notion that the underlying EP mechanism in patients with $\mathrm{BrS}$ is delayed depolarisation in the RV outflow tract (specifically over the anterior epicardial region) and demonstrates for the first time that substrate modification may be an effective strategy in patients with symptomatic BrS with recurrent VF episodes.

Flecainide has recently emerged as a promising new treatment for catecholaminergic polymorphic ventricular tachycardia (CPVT). In a mouse model of CPVT, flecainide was found to prevent arrhythmias by inhibiting cardiac ryanodine receptor-mediated calcium release. ${ }^{120}$ In the same publication, flecainide also completely prevented CPVT in two patients who had remained highly symptomatic with conventional drug treatment. In a clinical study of 33 patients who had received flecainide because of exercisedinduced ventricular arrhythmias despite conventional treatment, flecainide was found to either partially or completely reduce the arrhythmias in $76 \%$ of cases. ${ }^{121}$

\section{REFERENCES}

1. Healey JS, Baranchuk A, Crystal E, et al. Prevention of atrial fibrillation with angiotensin-converting enzyme inhibitors and angiotensin receptor blockers: a meta-analysis. J Am Coll Cardiol 2005;45:1832-9.

2. Disertori M, Latini R, Barlera S, et al. Valsartan for prevention of recurrent atrial fibrillation. $\mathrm{N}$ Engl J Med 2009;360:1606-17.

3. Yusuf S, Healey JS, Pogue J, et al. Irbesartan in patients with atrial fibrillation. N Engl J Med 2011;364:928-38.

4. Belluzzi F, Sernesi L, Preti P, et al. Prevention of recurrent lone atrial fibrillation by the angiotensin-II converting enzyme inhibitor ramipril in normotensive patients. J Am Coll Cardiol 2009;53:24-9.

5. Sun W, Sarma JS, Singh BN. Electrophysiological effects of dronedarone (SR33589), a noniodinated benzofuran derivative, in the rabbit heart: comparison with amiodarone. Circulation 1999;100:227681.

6. Hohnloser SH, Crijns HJ, van EM, et al. Effect of dronedarone on cardiovascular events in atrial fibrillation. N Engl J Med 2009;360:668-78.

7. Hohnloser SH, Crijns HJ, van EM, et al. Dronedarone in patients with congestive heart failure: insights from ATHENA. Eur Heart J 2010;31:1717-21.

8. Kober L, Torp-Pedersen C, McMurray JJ, et al. Increased mortality after dronedarone therapy for severe heart failure. N Engl J Med 2008;358:2678-87. 
9. Camm AJ, Kirchhof P, Lip GY, et al. Guidelines for the management of atrial fibrillation: the Task Force for the Management of Atrial Fibrillation of the European Society of Cardiology (ESC). Eur Heart J 2010;31:2369-429.

10. Wann LS, Curtis AB, January CT, et al. 2011 ACCF/ AHA/HRS focused update on the management of patients with atrial fibrillation (updating the 2006 guideline): a report of the American College of Cardiology Foundation/American Heart Association Task Force on Practice Guidelines. Circulation 2011;123:104-23.

11. Connolly SJ, Crijns HJ, Torp-Pedersen C, et al. Analysis of stroke in ATHENA: a placebo-controlled, double-blind, parallel-arm trial to assess the efficacy of dronedarone $400 \mathrm{mg}$ BID for the prevention of cardiovascular hospitalisation or death from any cause in patients with atrial fibrillation/atrial flutter. Circulation 2009;120:1174-80.

12. Page RL, Connolly SJ, Crijns HJ, et al. Rhythm- and rate-controlling effects of dronedarone in patients with atrial fibrillation (from the ATHENA trial). Am J Cardiol 2011;107:1019-22.

13. Fedida D, Orth PM, Chen JY, et al. The mechanism of atrial antiarrhythmic action of RSD1235. J Cardiovasc Electrophysiol 2005;16:1227-38.

14. Stiell IG, Roos JS, Kavanagh KM, et al. A multicenter, open-label study of vernakalant for the conversion of atrial fibrillation to sinus rhythm. Am Heart J 2010;159:1095-101.

15. Camm AJ, Capucci A, Hohnloser SH, et al. A randomized active-controlled study comparing the efficacy and safety of vernakalant to amiodarone in recent-onset atrial fibrillation. J Am Coll Cardiol 2011;57:313-21.

16. Shelton RJ, Clark AL, Goode K, et al. A randomised, controlled study of rate versus rhythm control in patients with chronic atrial fibrillation and heart failure: (CAFE-II Study). Heart 2009;95:924-30.

17. Van Gelder IC, Groenveld HF, Crijns HJ, et al. Lenient versus strict rate control in patients with atrial fibrillation. N Engl J Med 2010;362:1363-73.

18. Sakabe M, Shiroshita-Takeshita A, Maguy A, et al. Omega-3 polyunsaturated fatty acids prevent atrial fibrillation associated with heart failure but not atrial tachycardia remodeling. Circulation 2007;116:2101-9.

19. Ramadeen A, Laurent G, dos Santos CC, et al. n-3 Polyunsaturated fatty acids alter expression of fibrotic and hypertrophic genes in a dog model of atrial cardiomyopathy. Heart Rhythm 2010;7:520-8.

20. Virtanen JK, Mursu J, Voutilainen S, et al. Serum long-chain n-3 polyunsaturated fatty acids and risk of hospital diagnosis of atrial fibrillation in men. Circulation 2009;120:2315-21.

21. Kowey PR, Reiffel JA, Ellenbogen KA, et al. Efficacy and safety of prescription omega-3 fatty acids for the prevention of recurrent symptomatic atrial fibrillation: a randomized controlled trial. JAMA 2010;304:2363-72.
22. Bianconi L, Calo L, Mennuni M, et al. n-3 polyunsaturated fatty acids for the prevention of arrhythmia recurrence after electrical cardioversion of chronic persistent atrial fibrillation: a randomized, double-blind, multicentre study. Europace 2011;13:174-81.

23. Saravanan P, Bridgewater B, West AL, et al. Omega-3 fatty acid supplementation does not reduce risk of atrial fibrillation after coronary artery bypass surgery: a randomized, double-blind, placebo-controlled clinical trial. Circ Arrhythm Electrophysiol 2010;3:46-53.

24. Connolly SJ, Ezekowitz MD, Yusuf S, et al. Dabigatran versus warfarin in patients with atrial fibrillation. N Engl J Med 2009;361:1139-51.

25. Wann LS, Curtis AB, Ellenbogen KA, et al. 2011 ACCF/AHA/HRS focused update on the management of patients with atrial fibrillation (update on Dabigatran): a report of the American College of Cardiology Foundation/American Heart Association Task Force on practice guidelines. Circulation 2011;123:1144-50.

26. Wallentin L, Yusuf S, Ezekowitz MD, et al. Efficacy and safety of dabigatran compared with warfarin at different levels of international normalised ratio control for stroke prevention in atrial fibrillation: an analysis of the RE-LY trial. Lancet 2010;376:975-83.

27. Ezekowitz MD, Wallentin L, Connolly SJ, et al. Dabigatran and warfarin in vitamin $\mathrm{K}$ antagonistnaive and -experienced cohorts with atrial fibrillation. Circulation 2010;122:2246-53.

28. Nagarakanti R, Ezekowitz MD, Oldgren J, et al. Dabigatran versus warfarin in patients with atrial fibrillation: an analysis of patients undergoing cardioversion. Circulation 2011;123:131-6.

29. Connolly SJ, Pogue J, Hart RG, et al. Effect of clopidogrel added to aspirin in patients with atrial fibrillation. N Engl J Med 2009;360:2066-78.

30. Connolly S, Pogue J, Hart R, et al. Clopidogrel plus aspirin versus oral anticoagulation for atrial fibrillation in the Atrial fibrillation Clopidogrel Trial with Irbesartan for prevention of Vascular Events (ACTIVE W): a randomised controlled trial. Lancet 2006;367:1903-12.

31. Eikelboom JW, Weitz JI. New anticoagulants. Circulation 2010;121:1523-32.

32. Connolly SJ, Eikelboom J, Joyner C, et al. Apixaban in patients with atrial fibrillation. $\mathrm{N}$ Engl J Med 2011;364:806-17.

33. Holmes DR, Reddy VY, Turi ZG, et al. Percutaneous closure of the left atrial appendage versus warfarin therapy for prevention of stroke in patients with atrial fibrillation: a randomised non-inferiority trial. Lancet 2009;374:534-42.

34. Reddy VY, Holmes D, Doshi SK, et al. Safety of percutaneous left atrial appendage closure: results from the Watchman Left Atrial Appendage System for Embolic Protection in Patients with AF (PROTECT AF) clinical trial and the Continued Access Registry. Circulation 2011;123:417-24. 
35. Ostermayer SH, Reisman M, Kramer PH, et al. Percutaneous left atrial appendage transcatheter occlusion (PLAATO system) to prevent stroke in high-risk patients with non-rheumatic atrial fibrillation: results from the international multi-center feasibility trials. J Am Coll Cardiol 2005;46:9-14.

36. Block PC, Burstein S, Casale PN, et al. Percutaneous left atrial appendage occlusion for patients in atrial fibrillation suboptimal for warfarin therapy: 5 -year results of the PLAATO (Percutaneous Left Atrial Appendage Transcatheter Occlusion) Study. JACC Cardiovasc Interv 2009;2:594-600.

37. Cheng S, Keyes MJ, Larson MG, et al. Long-term outcomes in individuals with prolonged PR interval or first-degree atrioventricular block. JAMA 2009;301:2571-7.

38. Mymin D, Mathewson FA, Tate RB, et al. The natural history of primary first-degree atrioventricular heart block. N Engl J Med 1986;315:1183-7.

39. Schnabel RB, Sullivan LM, Levy D, et al. Development of a risk score for atrial fibrillation (Framingham Heart Study): a community-based cohort study. Lancet 2009;373:739-45.

40. Schnabel RB, Larson MG, Yamamoto JF, et al. Relations of biomarkers of distinct pathophysiological pathways and atrial fibrillation incidence in the community. Circulation 2010;121:200-7.

41. Patton KK, Ellinor PT, Heckbert SR, et al. Nterminal pro-B-type natriuretic peptide is a major predictor of the development of atrial fibrillation: the Cardiovascular Health Study. Circulation 2009;120:1768-74.

42. Kurl S, Ala-Kopsala M, Ruskoaho H, et al. Plasma $\mathrm{N}$-terminal fragments of natriuretic peptides predict the risk of stroke and atrial fibrillation in men. Heart 2009;95:1067-71.

43. Deftereos S, Giannopoulos G, Kossyvakis C, et al. Short-term fluctuations of plasma NT-proBNP levels in patients with new-onset atrial fibrillation: a way to assess time of onset? Heart 2010;96:1033-6.

44. Tedrow UB, Conen D, Ridker PM, et al. The longand short-term impact of elevated body mass index on the risk of new atrial fibrillation the WHS (women's health study). J Am Coll Cardiol 2010;55:2319-27.

45. Conen D, Tedrow UB, Cook NR, et al. Birth weight is a significant risk factor for incident atrial fibrillation. Circulation 2010;122:764-70.

46. Conen D, Chae CU, Glynn RJ, et al. Risk of death and cardiovascular events in initially healthy women with new-onset atrial fibrillation. JAMA 2011;305:2080-7.

47. Gudbjartsson DF, Arnar DO, Helgadottir A, et al. Variants conferring risk of atrial fibrillation on chromosome 4q25. Nature 2007;448:353-7.

48. Lubitz SA, Sinner MF, Lunetta KL, et al. Independent susceptibility markers for atrial fibrillation on chromosome 4q25. Circulation 2010;122:976-84.

49. Kaab S, Darbar D, van NC, et al. Large scale replication and meta-analysis of variants on chromosome
4 q25 associated with atrial fibrillation. Eur Heart J 2009;30:813-19.

50. Husser D, Adams V, Piorkowski C, et al. Chromosome $4 \mathrm{q} 25$ variants and atrial fibrillation recurrence after catheter ablation. J Am Coll Cardiol 2010;55:747-53.

51. Body SC, Collard CD, Shernan SK, et al. Variation in the 4q25 chromosomal locus predicts atrial fibrillation after coronary artery bypass graft surgery. Circ Cardiovasc Genet 2009;2:499-506.

52. Virani SS, Brautbar A, Lee VV, et al. Usefulness of single nucleotide polymorphism in chromosome $4 q 25$ to predict in-hospital and long-term development of atrial fibrillation and survival in patients undergoing coronary artery bypass grafting. Am J Cardiol 2011;107:1504-9.

53. Lubitz SA, Yin X, Fontes JD, et al. Association between familial atrial fibrillation and risk of newonset atrial fibrillation. JAMA 2010;304:2263-9.

54. Marcus GM, Alonso A, Peralta CA, et al. European ancestry as a risk factor for atrial fibrillation in African Americans. Circulation 2010;122:2009-15.

55. Wilber DJ, Pappone C, Neuzil P, et al. Comparison of antiarrhythmic drug therapy and radiofrequency catheter ablation in patients with paroxysmal atrial fibrillation: a randomized controlled trial. JAMA 2010;303:333-40.

56. Wokhlu A, Monahan KH, Hodge DO, et al. Longterm quality of life after ablation of atrial fibrillation the impact of recurrence, symptom relief, and placebo effect. J Am Coll Cardiol 2010;55:2308-16.

57. Weerasooriya R, Khairy P, Litalien J, et al. Catheter ablation for atrial fibrillation: are results maintained at 5 years of follow-up? J Am Coll Cardiol 2011;57:160-6.

58. Ouyang F, Tilz R, Chun J, et al. Long-term results of catheter ablation in paroxysmal atrial fibrillation: lessons from a 5-year follow-up. Circulation 2010;122:2368-77.

59. Hunter RJ, Berriman TJ, Diab I, et al. Long-term efficacy of catheter ablation for atrial fibrillation: impact of additional targeting of fractionated electrograms. Heart 2010;96:1372-8.

60. Oral H, Chugh A, Yoshida K, et al. A randomized assessment of the incremental role of ablation of complex fractionated atrial electrograms after antral pulmonary vein isolation for long-lasting persistent atrial fibrillation. J Am Coll Cardiol 2009;53:782-9.

61. Tokuda M, Yamane T, Matsuo S, et al. Relationship between renal function and the risk of recurrent atrial fibrillation following catheter ablation. Heart 2011;97:137-42.

62. Chao TF, Sung SH, Wang KL, et al. Associations between the atrial electromechanical interval, atrial remodelling and outcome of catheter ablation in paroxysmal atrial fibrillation. Heart 2011;97:225-30.

63. DW Den Uijl, V Delgado, M Bertini, et al. Impact of left atrial fibrosis and left atrial size on the outcome of catheter ablation for atrial fibrillation. Heart. Published Online First: 25 February 2011. 
doi:10.1136/hrt.2010.215335

64. Kuppahally SS, Akoum N, Badger TJ, et al. Echocardiographic left atrial reverse remodeling after catheter ablation of atrial fibrillation is predicted by preablation delayed enhancement of left atrium by magnetic resonance imaging. Am Heart J 2010;160:877-84.

65. Hussein AA, Saliba WI, Martin DO, et al. Plasma B-type natriuretic peptide levels and recurrent arrhythmia after successful ablation of lone atrial fibrillation. Circulation 2011;123:2077-82.

66. Mehta RH, Starr AZ, Lopes RD, et al. Incidence of and outcomes associated with ventricular tachycardia or fibrillation in patients undergoing primary percutaneous coronary intervention. JAMA 2009;301:1779-89.

67. Rashba EJ, Lamas GA, Couderc JP, et al. Electrophysiological effects of late percutaneous coronary intervention for infarct-related coronary artery occlusion: the Occluded Artery Trial-Electrophysiological Mechanisms (OAT-EP). Circulation 2009;119:779-87.

68. Bloch Thomsen PE, Jons C, Raatikainen MJ, et al. Long-term recording of cardiac arrhythmias with an implantable cardiac monitor in patients with reduced ejection fraction after acute myocardial infarction: the Cardiac Arrhythmias and Risk Stratification After Acute Myocardial Infarction (CARISMA) study. Circulation 2010;122:1258-64.

69. Wijnmaalen AP, Schalij MJ, von der Thusen JH, et al. Early reperfusion during acute myocardial infarction affects ventricular tachycardia characteristics and the chronic electroanatomic and histological substrate. Circulation 2010;121:1887-95.

70. Liew R. Prediction of sudden arrhythmic death following acute myocardial infarction. Heart 2010;96:1086-94.

71. Slawnych MP, Nieminen T, Kahonen M, et al. Post-exercise assessment of cardiac repolarization alternans in patients with coronary artery disease using the modified moving average method. J Am Coll Cardiol 2009;53:1130-7.

72. Costantini O, Hohnloser SH, Kirk MM, et al. The ABCD (Alternans Before Cardioverter Defibrillator) Trial: strategies using T-wave alternans to improve efficiency of sudden cardiac death prevention. J Am Coll Cardiol 2009;53:471-9.

73. Piccini JP, Starr AZ, Horton JR, et al. Single-photon emission computed tomography myocardial perfusion imaging and the risk of sudden cardiac death in patients with coronary disease and left ventricular ejection fraction $>35 \%$. J Am Coll Cardiol 2010;56:206-14.

74. Boogers MJ, Borleffs CJ, Henneman MM, et al. Cardiac sympathetic denervation assessed with 123-iodine metaiodobenzylguanidine imaging predicts ventricular arrhythmias in implantable cardioverter-defibrillator patients. J Am Coll Cardiol 2010;55:2769-77.

75. Iles L, Pfluger H, Lefkovits L, et al. Myocardial fibrosis predicts appropriate device therapy in patients with implantable cardioverter-defibrillators for primary prevention of sudden cardiac death. J Am Coll Cardiol 2011;57:821-8.

76. Kanoupakis EM, Manios EG, Kallergis EM, et al. Serum markers of collagen turnover predict future shocks in implantable cardioverter-defibrillator recipients with dilated cardiomyopathy on optimal treatment. J Am Coll Cardiol 2010;55:2753-9.

77. Kao WH, Arking DE, Post W, et al. Genetic variations in nitric oxide synthase 1 adaptor protein are associated with sudden cardiac death in US white community-based populations. Circulation 2009;119:940-51.

78. Arking DE, Khera A, Xing C, et al. Multiple independent genetic factors at NOS1AP modulate the QT interval in a multi-ethnic population. PLoS One 2009;4:e4333.

79. Hohnloser SH, Kuck KH, Dorian P, et al. Prophylactic use of an implantable cardioverter-defibrillator after acute myocardial infarction. N Engl J Med 2004;351:2481-8.

80. Dorian P, Hohnloser SH, Thorpe KE, et al. Mechanisms underlying the lack of effect of implantable cardioverter-defibrillator therapy on mortality in high-risk patients with recent myocardial infarction: insights from the Defibrillation in Acute Myocardial Infarction Trial (DINAMIT). Circulation 2010;122:2645-52.

81. Pouleur AC, Barkoudah E, Uno H, et al. Pathogenesis of sudden unexpected death in a clinical trial of patients with myocardial infarction and left ventricular dysfunction, heart failure, or both. Circulation 2010;122:597-602.

82. Shiga T, Hagiwara N, Ogawa H, et al. Sudden cardiac death and left ventricular ejection fraction during long-term follow-up after acute myocardial infarction in the primary percutaneous coronary intervention era: results from the HIJAMI-II registry. Heart 2009;95:216-20.

83. Steinbeck G, Andresen D, Seidl K, et al. Defibrillator implantation early after myocardial infarction. N Engl J Med 2009;361:1427-36.

84. Kuck KH, Schaumann A, Eckardt L, et al. Catheter ablation of stable ventricular tachycardia before defibrillator implantation in patients with coronary heart disease (VTACH): a multicentre randomised controlled trial. Lancet 2010;375:31-40.

85. Reddy VY, Reynolds MR, Neuzil P, et al. Prophylactic catheter ablation for the prevention of defibrillator therapy. N Engl J Med 2007;357:2657-65.

86. Schmidt B, Chun KR, Baensch D, et al. Catheter ablation for ventricular tachycardia after failed endocardial ablation: epicardial substrate or inappropriate endocardial ablation? Heart Rhythm 2010;7:1746-52.

87. Cano O, Hutchinson M, Lin D, et al. Electroanatomic substrate and ablation outcome for suspected epicardial ventricular tachycardia in left ventricular nonischemic cardiomyopathy. J Am Coll Cardiol 
2009;54:799-808.

88. Sacher F, Roberts-Thomson K, Maury P, et al. Epicardial ventricular tachycardia ablation a multicenter safety study. J Am Coll Cardiol 2010;55:2366-72.

89. Niwano S, Wakisaka Y, Niwano H, et al. Prognostic significance of frequent premature ventricular contractions originating from the ventricular outflow tract in patients with normal left ventricular function. Heart 2009;95:1230-7.

90. FD Munoz, FF Syed, A Noheria, et al. Characteristics of premature ventricular complexes as correlates of reduced left ventricular systolic function: study of the burden, duration, coupling interval, morphology and site of origin of PVCs. J Cardiovasc Electrophysiol. Published Online First: 18 February 2011. doi:10.1111/j.1540-8167.2011.02021.x.

91. Hasdemir C, Ulucan C, Yavuzgil O, et al. Tachycardia-induced cardiomyopathy in patients with idiopathic ventricular arrhythmias: the incidence, clinical and electrophysiologic characteristics, and the predictors. J Cardiovasc Electrophysiol 2011;22:663-8.

92. Wijnmaalen AP, Delgado V, Schalij MJ, et al. Beneficial effects of catheter ablation on left ventricular and right ventricular function in patients with frequent premature ventricular contractions and preserved ejection fraction. Heart 2010;96:1275-80.

93. Moss AJ, Hall WJ, Cannom DS, et al. Cardiac-resynchronization therapy for the prevention of heartfailure events. N Engl J Med 2009;361:1329-38.

94. Tang AS, Wells GA, Talajic M, et al. Cardiac-resynchronization therapy for mild-to-moderate heart failure. N Engl J Med 2010;363:2385-95.

95. Arshad A, Moss AJ, Foster E, et al. Cardiac resynchronization therapy is more effective in women than in men: the MADIT-CRT (Multicenter Automatic Defibrillator Implantation Trial with Cardiac Resynchronization Therapy) trial. J Am Coll Cardiol 2011;57:813-20.

96. Solomon SD, Foster E, Bourgoun M, et al. Effect of cardiac resynchronization therapy on reverse remodeling and relation to outcome: multicenter automatic defibrillator implantation trial: cardiac resynchronization therapy. Circulation 2010;122:985-92.

97. Daubert C, Gold MR, Abraham WT, et al. Prevention of disease progression by cardiac resynchronization therapy in patients with asymptomatic or mildly symptomatic left ventricular dysfunction: insights from the European cohort of the REVERSE (Resynchronization Reverses Remodeling in Systolic Left Ventricular Dysfunction) trial. J Am Coll Cardiol 2009;54:1837-46.

98. St John SM, Ghio S, Plappert T, et al. Cardiac resynchronization induces major structural and functional reverse remodeling in patients with $\mathrm{New}$ York Heart Association class I/II heart failure. Circulation 2009;120:1858-65.

99. Yu CM, Chan JY, Zhang Q, et al. Biventricular pacing in patients with bradycardia and normal ejection fraction. N Engl J Med 2009;361:2123-34.
100. Zareba W, Klein H, Cygankiewicz I, et al. Effectiveness of cardiac resynchronization therapy by QRS morphology in the Multicenter Automatic Defibrillator Implantation Trial-Cardiac Resynchronization Therapy (MADIT-CRT). Circulation 2011;123:1061-72.

101. Delgado V, van Bommel RJ, Bertini M, et al. Relative merits of left ventricular dyssynchrony, left ventricular lead position, and myocardial scar to predict long-term survival of ischemic heart failure patients undergoing cardiac resynchronization therapy. Circulation 2011;123:70-8.

102. Zhang Q, van Bommel RJ, Fung JW, et al. Tissue Doppler velocity is superior to strain imaging in predicting long-term cardiovascular events after cardiac resynchronisation therapy. Heart 2009;95:1085-90.

103. Singh JP, Klein HU, Huang DT, et al. Left ventricular lead position and clinical outcome in the multicenter automatic defibrillator implantation trial-cardiac resynchronization therapy (MADITCRT) trial. Circulation 2011;123:1159-66.

104. Derval N, Steendijk P, Gula LJ, et al. Optimizing hemodynamics in heart failure patients by systematic screening of left ventricular pacing sites: the lateral left ventricular wall and the coronary sinus are rarely the best sites. J Am Coll Cardiol 2010;55:566-75.

105. Ellenbogen KA, Gold MR, Meyer TE, et al. Primary results from the SmartDelay determined AV optimization: a comparison to other AV delay methods used in cardiac resynchronization therapy (SMARTAV) trial: a randomized trial comparing empirical, echocardiography-guided, and algorithmic atrioventricular delay programming in cardiac resynchronization therapy. Circulation 2010;122:2660-8.

106. Sagar S, Shen WK, Asirvatham SJ, et al. Effect of long-term right ventricular pacing in young adults with structurally normal heart. Circulation 2010;121:1698-705.

107. Galve E, Sambola A, Saldana G, et al. Late benefits of dual-chamber pacing in obstructive hypertrophic cardiomyopathy: a 10-year follow-up study. Heart 2010;96:352-6.

108. Parry SW, Steen N, Bexton RS, et al. Pacing in elderly recurrent fallers with carotid sinus hypersensitivity: a randomised, double-blind, placebo controlled crossover trial. Heart 2009;95:405-9.

109. Ryan DJ, Nick S, Colette SM, et al. Carotid sinus syndrome, should we pace? A multicentre, randomised control trial (Safepace 2). Heart 2010;96:347-51.

110. Tester DJ, Ackerman MJ. Genetic testing for potentially lethal, highly treatable inherited cardiomyopathies/channelopathies in clinical practice. Circulation 2011;123:1021-37.

111. Brugada R. Sudden death: managing the family, the role of genetics. Heart 2011;97:676-81.

112. Bastiaenen R, Behr ER. Sudden death and ion channel disease: pathophysiology and implications for management. Heart 2011;97:1365-72.

113. de Noronha SV, Sharma S, Papadakis M, et al. 
Aetiology of sudden cardiac death in athletes in the United Kingdom: a pathological study. Heart 2009;95:1409-14.

114. Krahn AD, Healey JS, Chauhan V, et al. Systematic assessment of patients with unexplained cardiac arrest: Cardiac Arrest Survivors With Preserved Ejection Fraction Registry (CASPER). Circulation 2009;120:278-85.

115. Crotti L, Monti MC, Insolia R, et al. NOS1AP is a genetic modifier of the long-QT syndrome. Circulation 2009;120:1657-63.

116. Arking DE, Pfeufer A, Post W, et al. A common genetic variant in the NOS1 regulator NOS1AP modulates cardiac repolarization. Nat Genet 2006;38:644-51.

117. Tomas M, Napolitano C, De GL, et al. Polymorphisms in the NOS1AP gene modulate QT interval duration and risk of arrhythmias in the long QT syndrome. J Am Coll Cardiol 2010;55:2745-52.

118. Probst V, Veltmann C, Eckardt L, et al. Long-term prognosis of patients diagnosed with Brugada syndrome: results from the FINGER Brugada Syndrome Registry. Circulation 2010;121:635-43.

119. Lambiase PD, Ahmed AK, Ciaccio EJ, et al. Highdensity substrate mapping in Brugada syndrome: combined role of conduction and repolarization heterogeneities in arrhythmogenesis. Circulation 2009;120:106-4.

120. Watanabe H, Chopra N, Laver D, et al. Flecainide prevents catecholaminergic polymorphic ventricular tachycardia in mice and humans. Nat Med 2009;15:380-3.

121. van der Werf C, Kannankeril PJ, Sacher F, et al. Flecainide therapy reduces exercise-induced ventricular arrhythmias in patients with catecholaminergic polymorphic ventricular tachycardia. J Am Coll Cardiol 2011;57:2244-54.

Corresponding author: Reginald Liew, MD. Department of Cardiology. National Heart Centre Singapore. 17 Third Hospital Avenue, Singapore. E-mail: reginald.liew.k.c@nhcs.com.sg

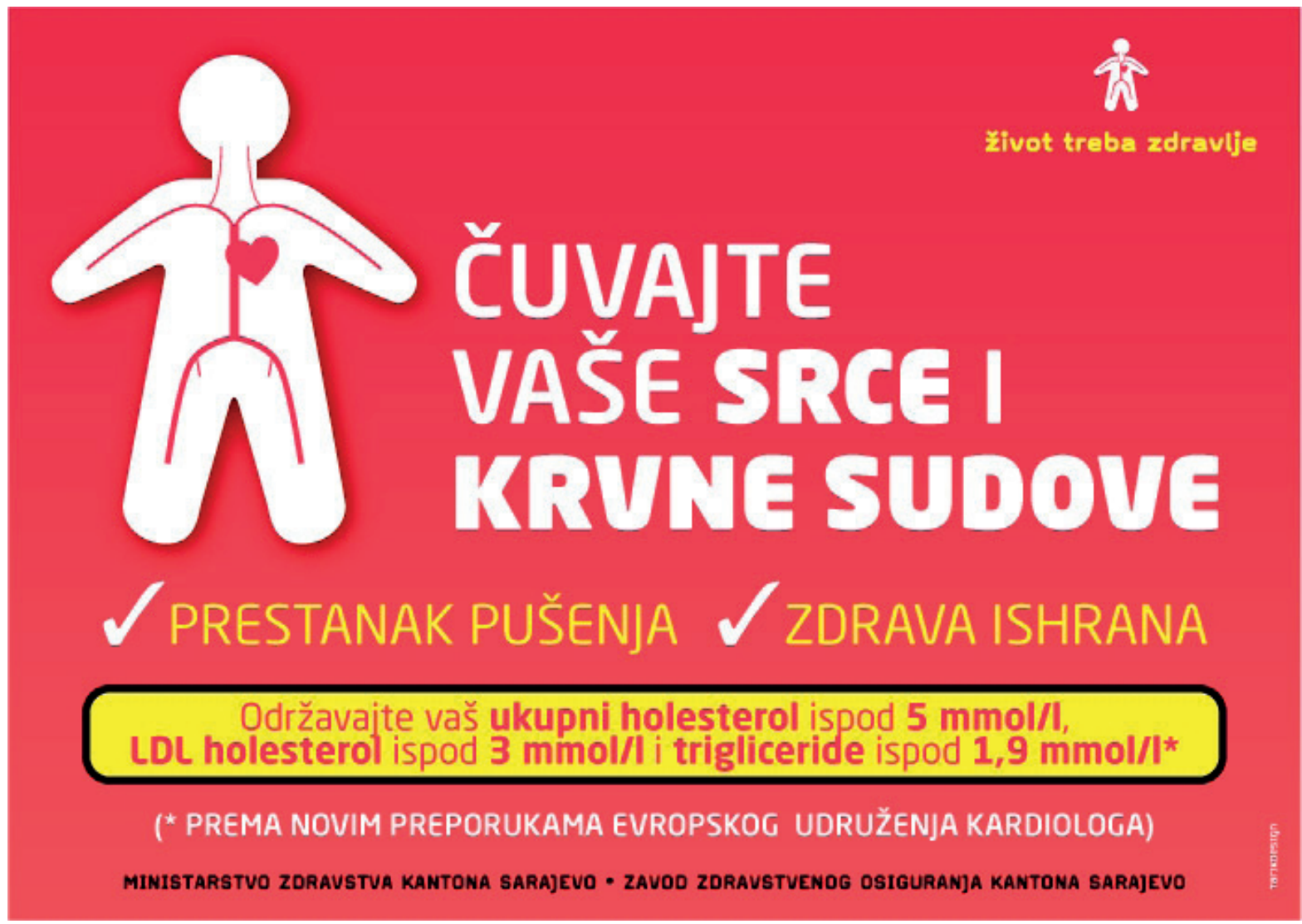

